\title{
Quality evaluation based on color grading - relationship between chemical substances and commercial grades by machine vision in Corni fructus
}

\author{
Yongxia Cui, Lili Wang, Liangliang Duan, Suiqing Chen* \\ Henan University of Chinese Medicine, Zhengzhou, Henan, China, 450046 \\ *For correspondence: Email: suiqingchen0371@163.com; Tel: +86-371-65676686 \\ Sent for review: 16 September 2019 \\ Revised accepted: 21 June 2020
}

\begin{abstract}
Purpose: To evaluate the correlation between the commercial grade of Corni fructus determined by machine vision technology, and its chemical composition.

Methods: Loganin, morroniside, ursolic acid, water-soluble extractives, alcohol-soluble extractives, polysaccharides and total organic acids were quantitated in four Corni fructus grades classified by machine vision technology. The content of each component was determined and analyzed by mathematical statistics.

Results: Compared with low-grade samples, higher-grade counterparts contained elevated concentrations of alcohol-soluble extractives, water-soluble extractives, loganin and morroniside. In addition, principal component analysis revealed a correlation coefficient of -0.723 between Corni fructus grade and Holistic Scoring based on chemical composition, indicating a significant correlation $(p<0.01)$. Conclusion: These findings indicated the rationality of the classification method based on machine vision, and further confirmed the notion of "quality evaluation based on color" of traditional Chinese medicine.
\end{abstract}

Keywords: Corni fructus, Commercial grade, Machine vision technology, Chemical substance

\begin{abstract}
This is an Open Access article that uses a fund-ing model which does not charge readers or their institutions for access and distributed under the terms of the Creative Commons Attribution License (http://creativecommons.org/licenses/by/4.0) and the Budapest Open Access Initiative (http://www.budapestopenaccessinitiative.org/read), which permit unrestricted use, distribution, and reproduction in any medium, provided the original work is properly credited.

Tropical Journal of Pharmaceutical Research is indexed by Science Citation Index (SciSearch), Scopus, International Pharmaceutical Abstract, Chemical Abstracts, Embase, Index Copernicus, EBSCO, African Index Medicus, JournalSeek, Journal Citation Reports/Science Edition, Directory of Open Access Journals (DOAJ), African Journal Online, Bioline International, Open-J-Gate and Pharmacy Abstracts
\end{abstract}

\section{INTRODUCTION}

Corni fructus, or Asiatic cornelian cherry fruit, is the dried ripe sarcocarp of Cornus officinalis Sieb. et Zucc. (Fam. Cornaceae). The fruit is harvested in late autumn and early winter when the pericarp turns red, baked over a soft fire or briefly boiled in water, timely removed from the kern and dried. Corni fructus was firstly described in Shennong's Classic of Materia Medica nearly 2000 years ago under the term
"Shan Zhuyu", advising that "long-term consumption may prolong life". It is a popular clinical medicine used to tonify and nourish the kidney and liver, and has astringent features for the skin. The annual demand of Corni fructus approximates 6000 tons in China. Previous findings revealed that iridoid glycosides, organic acids, polyphenols, and alcohol- and water-soluble extractives of Corni fructus exhibit extensive pharmacological activities, including anti-inflammatory effects, diabetes prevention 
and treatment, protection of cardiovascular and cerebrovascular systems, neuroprotection, and anti-tumor, anti-oxidative and anti-aging effects [1]. It also comprises nutrients such as polysaccharides, amino acids, minerals and immunity-improving vitamins. Therefore, this fruit is widely used as medicine and food in China. In addition, it contains pigments, such as flavonoids, anthocyanins and other polyphenols [2], whose contents and ratios are responsible for the characteristic color of "Shan Zhuyu", which in turn determines its economic value. Market investigation shows that improper storage conditions or prolonged storage durations result in fruit color change from bright red to purpleblack. Such changes significantly reduce its economic value as well as the quality of medicinal constituents, thus affecting its effects.

On the Chinese market, Corni fructus is not graded by quantitating the aforementioned chemical components; instead, organoleptic evaluation by machine vision technology is applied. Machine vision is a newly developed technology, which is widely used in the food industry because of its efficiency, accuracy and non-destructive nature [3]. To date, machine vision technology has multiple functions, including grading and selection of foods such as coffee beans, citrus, and beef [4-6]; chemical analysis [7], and quality evaluation [8].

Color is one of the most important food attributes, and strongly affects product acceptance by customers. Corni fructus is no exception, and samples are classified and priced according to grade. The brighter the color, the higher the grade. High grade samples cost from $\$ 25$ to \$27 per kilogram, while low grade specimens are sold for $\$ 13$ to $\$ 15$. The foregoing indicates that the judgment ability and accuracy of machine vision technology could influence the price. This work aimed to evaluate the associations of multiple constituents of Corni Fructus with commercial grade obtained by organoleptic evaluation. Chemical constituents associated with the color, taste, and extensive pharmacological features of watersoluble extractives, alcohol-soluble extractives, polysaccharides, total organic acids, were assessed, alongside loganin, morroniside and ursolic acid.

\section{EXPERIMENTAL}

\section{Samples}

A total of 65 Corni fructus specimens were purchased from the main production areas in Henan, Zhejiang, Shanxi and Shaanxi provinces, as well as Traditional Medicinal Materials markets in China. All samples were authenticated by Professor Suiqing Chen and other experts at the Teaching and Research Center of Identification of traditional Chinese medicine (TCM), Henan University of Chinese Medicine. Sample grading based on organoleptic properties was performed by machine vision technology (IRIS VA400 E-Eye, Alpha, M.O.S, Toulouse, France). Then, the samples were classified as grades $A$ ( $n=7$; highest grade), $B$ $(n=36), C(n=8)$, and $D(n=14$; lowest grade). Representative samples for various grades are shown in Figure 1.

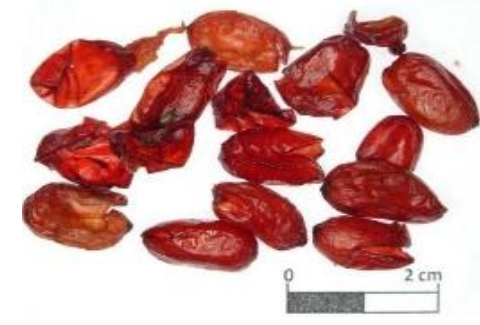

Grade A
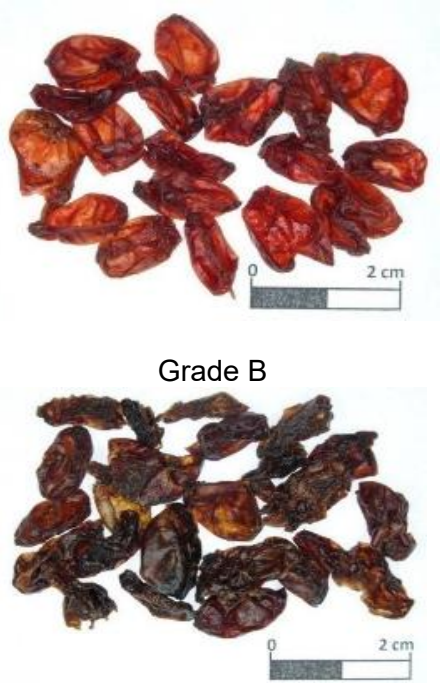

Grade C

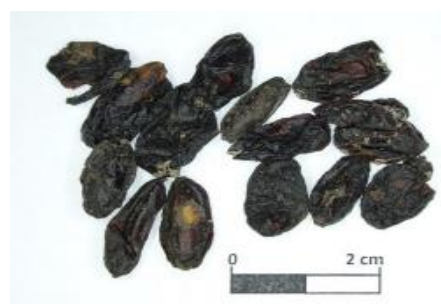

Grade D

Figure 1: Representative samples of various Corni fructus grades 


\section{Chemicals and standards}

Loganin, morroniside, ursolic acid, tartaric acid, and glucose standards were purchased from the National Institutes of Food and Drug Control (Beijing, China). The purity of each reference compound was > $98 \%$ as determined by high performance liquid chromatography (HPLC). HPLC-grade acetonitrile and methanol were obtained from Tedia Inc. (Fair-filed, OH, USA). Other reagents were of analytical grade. Water was prepared on a Millipore Milli-Q purification system (Millipore Crop., Bedford, MA, USA).

\section{Loganin and morroniside quantitation}

Loganin and morroniside contents were determined according to the 2015 Edition of the Chinese Pharmacopoeia. Chromatographic analyses were performed on an Agilent 1260 series (Agilent, California, USA) equipped with a G1311C pump, a G1315D DAD (240 nm), a G1316A column oven $\left(35{ }^{\circ} \mathrm{C}\right)$, and a G1329B auto-sampler. The column was an $\mathrm{SB}^{-\mathrm{C}_{18}}(4.6$ $\mathrm{mm} \times 250 \mathrm{~mm}, 5 \mu \mathrm{m})$ (Agilent, California, USA). The mobile phase comprised phosphoric acid $\left(\mathrm{H}_{3} \mathrm{PO}_{4}\right)$ aqueous solution $(0.3: 100, \mathrm{v} / \mathrm{v})(\mathrm{A})$ and acetonitrile $(\mathrm{B})$, with the following gradient elution program: 0 to $20 \mathrm{~min}, 7 \% \mathrm{~B} ; 20$ to $50 \mathrm{~min}, 7$ to $20 \% \mathrm{~B}$. A flow rate of $1.0 \mathrm{~mL} / \mathrm{min}$ was used and injection volume (reference or sample solution) was $10 \mu \mathrm{l}$. For sample preparation, $0.2 \mathrm{~g}$ of powder (particle diameter: $355 \pm 13 \mu \mathrm{m}$ ) was weighed accurately in a stoppered conical flask. Then, $25 \mathrm{~mL}$ of $80 \%$ methanol was added and the mixture was weighed. After heating under reflux for 1 hour, the sample was cooled and weighed again, the weight deficit was replenished with $80 \%$ methanol. The resultant sample was mixed well, filtered and used as the test solution. Before injection into the HPLC system, all samples were filtered through 0.45 $\mu \mathrm{m}$ filter membranes. Meanwhile, precisely weighed loganin and morroniside standards were added to $80 \%$ methanol for preparing mixed samples with 66 and $62 \mu \mathrm{g} / \mathrm{mL}$ as reference solutions, respectively. Reference and test samples (10 $\mu \mathrm{L}$ each) were assessed by HPLC.

\section{Quantitation of Ursolic acid}

The quantitation of ursolic acid was performed via HPLC. Chromatographic analyses were performed on an Agilent 1260 series. Detection was carried out at $215 \mathrm{~nm}$. The mobile phase was $0.1 \%$ phosphoric acid $\left(\mathrm{H}_{3} \mathrm{PO}_{4}\right)$ in water mixed with methanol (90:10). A flow rate of 0.6 $\mathrm{mL} / \mathrm{min}$ was used, and injection volume was 10 $\mu \mathrm{L}$. For sample preparation, $1.0 \mathrm{~g}$ of powder was passed through a No.3 sieve and weighed in a stopper equipped conical flask; $25 \mathrm{~mL}$ of methanol was added and the mixture was weighed. After ultrasonication at $250 \mathrm{~W}$ and 80 $\mathrm{kHz}$ for $45 \mathrm{~min}$, the samples were cooled and weighed again. The weight deficit was replenished with methanol, and the sample was mixed well, filtered and the filtrate was used as the test solution. Before HPLC assessment, all samples underwent filtration through $0.45-\mu \mathrm{m}$ pore membranes. Ursolic acid standard was added to methanol for preparing a reference solution at $86 \mu \mathrm{g} / \mathrm{mL}$. Reference and test samples (10 $\mu \mathrm{L}$ each) were assessed by HPLC.

\section{Determination of polysaccharides}

Polysaccharides of Corni fructus were quantitated by the phenol-sulfuric acid method [9]. Anhydrous glucose standard was weighed, dissolved in water to prepare a solution containing $0.1 \mathrm{mg} \cdot \mathrm{ml}^{-1}$. The reference standards were prepared by placing exactly $0.1,0.3,0.6$, 1.0 and $1.5 \mathrm{~mL}$ of reference solutions, respectively, in $10 \mathrm{~mL}$ volumetric flasks, followed by water addition (to $10 \mathrm{~mL}$ ) and mixing. From each solution, $2 \mathrm{~mL}$ was transferred to tubes, and $1 \mathrm{~mL}$ of $4 \%$ phenol solution was added and mixed well. Then, $7.0 \mathrm{~mL}$ of sulfuric acid was added quickly and incubated at $40{ }^{\circ} \mathrm{C}$ in a water bath with shaking for $30 \mathrm{~min}$. The samples were moved to an ice bath for $5 \mathrm{~min}$. Absorbance was measured at $510 \mathrm{~nm}$, with the corresponding solvent as a blank control. A standard curve was plotted with absorbance as ordinate and concentration as abscissa. The pulverized fruit sample $(0.1 \mathrm{~g})$ was placed in a round-bottom flask, and $50 \mathrm{~mL}$ of $80 \%$ ethanol was added and heated under reflux in a water bath for $1 \mathrm{~h}$. After filtration, the residue was washed with $40 \mathrm{~mL}$ of $80 \%$ hot ethanol. The residue and the filter paper were transferred to a flask, and $40 \mathrm{~mL}$ of water was added, heated under reflux for $1 \mathrm{~h}$ and filtered. The resulting residue and the flask were washed with $40 \mathrm{ml}$ of hot water. After combining the filtrates and wash solvents, chloroform nbutanol (3:2) (20 mL) was used for extraction, repeated once. The upper layer of water was transferred into a $100 \mathrm{~mL}$ volumetric flask, diluted with water to volume and mixed well. Then, $1 \mathrm{~mL}$ of this solution was added to a $10 \mathrm{~mL}$ dry test tube. As described above for the calibration standard, $1 \mathrm{ml}$ of $4 \%$ phenol solution was added, and absorbance was measured at $510 \mathrm{~nm}$. Glucose (mg) in the test solution was derived from the standard curve.

\section{Quantitation of total organic acids}

Total organic acids of Corni fructus were determined by the second-order derivative 
potentiometric titration method [10]. Tartaric acid standard dried to constant weight was weighed, and dissolved in $80 \%$ ethanol to prepare the reference solution at $15.0 \mathrm{mg} / \mathrm{mL}$. Then, 5, 8, 15, 25 and $30 \mathrm{~mL}$ of the reference solution were added to $50 \mathrm{~mL}$ volumetric flasks, diluted with 80 $\%$ ethanol to volume and mixed well. Next, 20 $\mathrm{mL}$ of various reference solutions were transferred, respectively, to $100 \mathrm{~mL}$ beakers, which were placed on a magnetic stirrer. Electrodes were dipped into the solutions under stirring. The titrant from a burette was added in portions, and the $\mathrm{pH}$ was recorded after each addition. When the end point was nearly reached, the titration solution was added dropwise and the $\mathrm{pH}$ was recorded; a few more drops were added after the inflection point, and the $\mathrm{pH}$ was recorded. In the second method, a curve was generated with $\Delta^{2} \mathrm{pH} / \Delta \mathrm{V}^{2}$ as the ordinate and the corresponding volume of titration solution $(\mathrm{V})$ as the abscissa, with the end point occurring at the volume $(\mathrm{V})$ with $\Delta^{2} \mathrm{pH} / \Delta \mathrm{V}^{2}=$ 0 . A total of $5.0 \mathrm{~g}$ of powder was placed in a stoppered conical flask, and $50 \mathrm{ml}$ of $80 \%$ ethanol was added. After ultrasonication at 250 W and $80 \mathrm{kHz}$ for $30 \mathrm{~min}$ and filtration, the residue was ultrasonicated again in $50 \mathrm{~mL}$ of 80 $\%$ ethanol as described above. Upon filtration, the mixed filtrate was transferred into $100 \mathrm{~mL}$ volumetric flasks, diluted with $80 \%$ ethanol and mixed well. Then, $20 \mathrm{~mL}$ was measured with 100 $\mathrm{mL}$ beakers for $\mathrm{pH}$ measurement, and $\Delta^{2} \mathrm{pH} / \Delta \mathrm{V}^{2}$ was derived. The titrant volume $(\mathrm{mL})$ in the sample was obtained from the standard curve, to calculate the content.

\section{Quantitation of water-soluble extractives}

The water-soluble extractives were determined via the method published by the 2015 Edition of the Chinese Pharmacopoeia. A total of $4.0 \mathrm{~g}$ of the powdered material (particle size, $850 \pm 29$ $\mu \mathrm{m})$, was added to a $250 \mathrm{~mL}$ stopper-equipped conical flask, and $100 \mathrm{ml}$ of water was supplemented. The drug was macerated with shaking for $6 \mathrm{~h}$ and allowed to stand for $18 \mathrm{~h}$. After filtration, $20 \mathrm{~mL}$ of filtrate was transferred accurately to an evaporating dish previously dried to constant weight, evaporated to dryness in a water bath, dried at $105^{\circ} \mathrm{C}$ for $3 \mathrm{~h}$, and allowed to cool for $30 \mathrm{~min}$ in a desiccator. The extract was weighed, and the percentage of water-soluble extract was calculated after drying.

\section{Assessment of alcohol-soluble extractives}

The procedure was carried out according to the 2015 Edition of the Chinese Pharmacopoeia as described under "Assay of water- soluble extractives", with water replaced by $95 \%$ ethanol.

\section{Determination of water content}

The procedure was carried out according to the 2015 Edition of the Chinese Pharmacopoeia. A total of $3 \mathrm{~g}$ of powder (particle size: $850 \pm 29$ $\mu \mathrm{m})$, was placed in a flat weighing bottle previously dried to constant weight to form a smooth layer not exceeding $5 \mathrm{~mm}$ in thickness, weighed, and dried in an oven at $105{ }^{\circ}$ Cfor $5 \mathrm{~h}$ with the bottle stopper removed. Upon opening the oven, the bottle was closed promptly and allowed to cool in a desiccator for $30 \mathrm{~min}$. After weighing and further drying under similar conditions for $1 \mathrm{~h}$, the sample was cooled and weighed. The operation was repeated until the difference between two successive weighs did not exceed $5 \mathrm{mg}$. The percentage content of water was calculated according to weight loss during drying. The actual level of each component of Corni fructus was determined by taking into account the water content.

\section{Statistical analysis}

Data are expressed as mean \pm standard error of the mean (SEM), and were analyzed with SPSS 18.0 (SPSS, Inc., Chicago, IL, USA). Data were assessed for statistical significance using oneway ANOVA, followed by Fisher's least significant difference (LSD) post-hoc test for pair group comparisons. $P<0.05$ was considered statistically significant.

\section{Principal component analysis (PCA)}

Principal component analysis (PCA) starts with the relationship among multiple indicators and reduces the dimensionality of the indicators to a few irrelevant main components. These main components are linear combinations of the original indicators, which not only retain the main information of the original indicators, but also are irrelevant to each other. PCA was carried out for samples of different grades. The characteristic $\mathrm{c}$ values, cumulative contribution rates and Holistic Scoring $F$ values of PCA were calculated. The $F$ value was used to characterize the chemical evaluation of each sample. The variance analysis of the $F$ value was carried out to test whether there was correlation between the grade of corni fructus based on color classification, and chemical evaluation.

\section{RESULTS}

The contents of loganin, morroniside, ursolic acid, polysaccharides, total organic acids, water- 
soluble extractives, and alcohol-soluble extractives in dry samples are presented in Table 1.

\section{Loganin and morroniside contents}

Loganin content showed a significant difference between grade A (1.63 $\pm 0.41 \%)$ and Grade C $(0.79 \pm 0.18 \%)$ samples. The amounts of morroniside in grade $\mathrm{A}(3.05 \pm 0.55 \%)$ and grade B (3.05 $\pm 0.53 \%)$ samples were higher than those of other grades.

\section{Polysaccharide content}

The polysaccharide content seemed to be similar among different grades assessed using machine vision. The content of polysaccharides tended to be lower in grade D $(7.02 \pm 0.69 \%)$ samples than in the remaining grades; however, the difference was not statistically significant. The polysaccharides of Corni fructus have many health care benefits, including anti-inflammatory, anti-shock, anti-aging, and immunoregulatory activities [11]. Polysaccharides represent important constituents of this fruit utilized as medicine and food, but their content did not overtly alter sample color.

Contents of ursolic acid and total
organic acids

The amounts of ursolic acid were overtly different between Grade B $(0.164 \pm 0.028 \%)$ and Grade D $(0.142 \pm 0.045 \%)$ samples. The total organic acid content was higher in Grade A (1.99 $\pm 0.25 \%$ ) samples when compared with Grade D $(1.67 \pm 0.18 \%)$ specimens. The results showed that ursolic acid and organic acid contents were significantly reduced in grade D samples.

\section{Water-soluble extractives}

The contents of water-soluble extractives decreased as the grade decreased, and grade $D$ $(64.77 \pm 2.50 \%)$ content was significantly lower than those of other grades. In the Chinese
Pharmacopoeia, water-soluble extractives content is one of the quality control, and should not be below 50.0 percent.

\section{Alcohol-soluble extractives}

Alcohol-soluble extract contents are expected to increase with sample Grade. The contents of grade $A(54.82 \pm 2.87 \%)$ samples were higher than those of the remaining grades, with grade $D$ samples showing significantly lower amounts $(36.82 \pm 5.35 \%)$ compared with higher grade specimens. The differences were statistically significant.

\section{Correlation analysis between each index and grade}

The results of correlation analysis between indicators and grades were shown in Table 2. A correlation coefficient of - 0.130 was found between polysaccharide content and grade, although the correlation showed no statistical significance $(p>0.05)$. Although the content of loganin, ursolic acid and organic acid was significantly or highly significantly correlated with grade, the correlation coefficient was less than 0.5 , indicating no statistical significance. The correlation coefficients between the content of morroniside, water-soluble extractives, alcoholsoluble extractives and grade were - 0.644, 0.530 , - $0.757(p<0.01)$, respectively, which showed a moderate linear correlation statistically, indicating that there was a certain correlation between the grade classification of appearance color and these chemical components.

\section{Principal component eigenvalue and rate of variance}

The eigenvalues and the percent of variance are shown in Table 3. Based on total cumulative greater than $70 \%, 3$ principal components were obtained, with eigenvalues of $2.332,1.610$ and 1.076 , and percentages of variance of 33.307 , 23.005 , and $15.368 \%$, respectively.

Table 1: Contents of loganin, morroniside, ursolic acid, total organic acids, polysaccharides, water-soluble extractives, and alcohol-soluble extractives in various grades of Corni fructus. Values are mean \pm standard deviation (SD). Values in the same row with different letters are significantly different $(p<0.05)$

\begin{tabular}{lcccc}
\hline Grade & Grade A & Grade B & Grade C & Grade D \\
\hline Loganin (\% ) & $1.71 \pm 0.41^{a}$ & $1.42 \pm 0.71^{a b}$ & $0.857 \pm 0.194^{b}$ & $1.10 \pm 0.22^{b}$ \\
Morroniside (\% ) & $3.37 \pm 0.59^{a}$ & $3.36 \pm 0.51^{a}$ & $2.65 \pm 0.49^{b}$ & $2.36 \pm 0.25^{b}$ \\
Ursolic acid (\% ) & $0.158 \pm 0.031^{a b}$ & $0.164 \pm 0.028^{a}$ & $0.153 \pm 0.024^{a b}$ & $0.142 \pm 0.045^{b}$ \\
Total organic acids (\% ) & $1.99 \pm 0.25^{a}$ & $1.80 \pm 0.26^{a b}$ & $1.81 \pm 0.20^{a b}$ & $1.67 \pm 0.18^{b}$ \\
Polysaccharides (\% ) & $7.51 \pm 1.63^{a}$ & $7.66 \pm 2.01^{a}$ & $7.52 \pm 0.84^{a}$ & $7.02 \pm 0.69^{a}$ \\
Water-soluble extractives (\% ) & $71.90 \pm 2.30^{a}$ & $69.98 \pm 4.47^{a}$ & $68.16 \pm 2.77^{a}$ & $64.77 \pm 2.50^{b}$ \\
Alcohol-soluble extractives (\% ) & $54.82 \pm 2.87^{a}$ & $49.23 \pm 5.23^{b}$ & $44.18 \pm 4.97^{c}$ & $36.82 \pm 5.35^{d}$ \\
\hline
\end{tabular}


Table 2: Correlation between each index and grade

\begin{tabular}{cccccccc}
\hline Grade & $\begin{array}{c}\text { Loganin } \\
(\%)\end{array}$ & $\begin{array}{c}\text { Monoside } \\
(\%)\end{array}$ & $\begin{array}{c}\text { Ursolic } \\
\text { acid } \\
(\%)\end{array}$ & $\begin{array}{c}\text { Polysacchari } \\
\text { de (\%) }\end{array}$ & $\begin{array}{c}\text { Water- } \\
\text { Organic } \\
\text { acid (\%) }\end{array}$ & $\begin{array}{c}\text { soluble } \\
\text { extractives } \\
(\%)\end{array}$ & $\begin{array}{c}\text { Alcohol- } \\
\text { soluble } \\
\text { extractives (\%) }\end{array}$ \\
\hline Grade & $-.340^{* *}$ & $-.644^{* *}$ & $-.225^{*}$ & -.130 & $-.321^{* *}$ & $-.530^{* *}$ & $-.757^{* *}$ \\
\hline
\end{tabular}

${ }^{\star}$ Correlation is significant $(p<0.05) ;{ }^{* *}$ Correlation is significant at the 0.01 level

Therefore, the total cumulative was $71.68 \%$, and the main information of the source data could be due to the contents of loganin, morroniside, ursolic acid and total organic acids. Thus, the water-soluble extract and the alcoholsoluble extract are related to the grade.

\section{DISCUSSION}

Iridoid glycosides are relatively active and prone to polymerization, resulting in decreased content and browning of Corni fructus. This would be one of the causes of color darkening of grade $C$ and grade D samples. Small molecular weight organic acids, including tartaric, malic, and gallic acids are directly related to the sour taste. With extended storage time, corni fructus grade is reduced, and the sour taste also fades, which might be consistent with the data for total organic acid content. The water-soluble extract contains mainly water-soluble pigments, tannins, polysaccharides, iridoid glycosides, water-soluble vitamins, small organic acids, water-soluble proteins and inorganic salt.

Oxidation or polymerization of polyphenols such as water-soluble pigments, tannins and iridoid glycosides during storage might lead to decreased water-soluble extract content, which may be another reason behind the color darkening of Grade D samples. The alcoholsoluble extract contains mainly flavonoids, iridoid glycosides, and phenylpropanoids. The color of Corni fructus is attributed to lipophilic pigments such as flavonols, dihydroflavonoids and anthocyanins, most of which are polyphenols. Phenolic pigments are easily oxidized during storage, and oxidation is one of the main factors causing color deepening and affecting the quality and commercial value of Corni fructus. Previous studies have shown that pigments account for 25 - $28 \%$ of the ethanol extract [12]. Therefore, the color of grade A samples was brighter than those of samples of other grades.

\section{CONCLUSION}

The commercial grade of TCM is a standard formed naturally in the course of the market transaction, and it is comprehensive and unique for the evaluation of the quality of TCM. The results of this study show that there is a significant correlation between the classification judged by machine vision technology and its pharmacodynamic components. This lends the scientific support for the traditional identification method of TCM "quality evaluation based on color grading", and thus provides guidance and reference for the accurate application of Corni fructus in clinic and health products.

\section{DECLARATIONS}

\section{Acknowledgement}

The authors would like to acknowledge the support provided by the National Survey of Chinese Medicine Resources (Finance and Social Council, no. 2017 66), a special grant for public health services of Chinese medicine in 2017. We thank Alphor MOS Company for technical support.

\section{Conflict of interest}

The authors declare that they have no known competing financial interests or personal relationships that influenced the work reported in this paper.

\section{Contribution of authors}

We declare that this work was done by the authors named in this article and all liabilities pertaining to claims relating to the content of this article will be borne by the authors. Yongxia Cui performed the experiments, analyzed the data and wrote the paper; Lili Wang conceived and designed the experiments and analyzed the data; Liangliang Duan contributed reagents/materials and performed the E-eye test; Suiqing Chen coordinated the resources.

\section{Open Access}

This is an Open Access article that uses a funding model which does not charge readers or their institutions for access and distributed under the terms of the Creative Commons Attribution License (http://creativecommons.org/licenses/by/ 
4.0) and the Budapest Open Access Initiative (http://www.budapestopenaccessinitiative.org/rea d), which permit unrestricted use, distribution, and reproduction in any medium, provided the original work is properly credited.

\section{REFERENCES}

1. Huang J, Zhang YW, Dong L, Gao QH, Yin L, Quan, HF, Chen $R$, Fu $X Y$, Lin DB. Ethnopharmacology, phytochemistry, and pharmacology of Cornus officinalis Sieb. et Zucc. J Ethnopharmacol 2018; 213: 280-301.

2. Ye Xiansheng. Studies on Chemical Constituents and Bioactivities of Cornus officinalis [D]. Beijing University of Chinese Medicine, Beijing, China, 2017.

3. Gomes JFS, Leta FR. Applications of computer vision techniques in the agriculture and food industry: a review. Eur Food Res Technol 2012: 235(6): 989-1000.

4. Portugal Zambrano C, Gutierrez-Caceres J C, RamirezTicona J, Beltran-Castanon C A. Computer vision grading system for physical quality evaluation of green coffee beans. 2016 XLII Latin American Computing Conference (CLEI),2016.

5. Cubero S, Aleixos N, Albert F, Torregrosa A, Ortiz C, Garcia-Navarrete $O$, Blasco J. Optimised computer vision system for automatic pre-grading of citrus fruit in the field using a mobile platform. Precis Agric 2013; 15(1): 80-94.
6. Chen K, Sun X, Qin C, Tang X. Color grading of beef fat by using computer vision and support vector machine. Comput Electron Agric 2010; 70(1): 27-32.

7. Pace B, Cefola $M$, Renna $F$, Renna $M$, Serio $F$, Attolico G. Multiple regression models and Computer Vision Systems to predict antioxidant activity and total phenols in pigmented carrots. J Food Eng 2013; 117(1): 74-81.

8. Ryusuke Tanakaa, Mami Ishimarua, Hideo Hatatea, Yoshimasa Sugiurab, Teruo Matsushitab. Relationship between 4-hydroxy-2-hexenal contents and commercial grade by organoleptic judgement in Japanese dried laver Porphyra spp. Food Chem 2016; 05: 166.

9. Chen Suiqing, Li Jun, Li Xueju. Dynamic accumulation of polysaccharides in Cornus officinalis during different growth stages. Zhongguo Shi Yan Fang Ji Xue Za Zhi 2009; 15(1): 1-2.

10. Chen Leilei, Chen Suiqing, Wang Jing. Study on the content of Total Organic acids in Fructus Corni at different harvesting stages. World $\mathrm{J}$ Tradit Chin Med 2011; 6(3): 268-269.

11. Wu $Y$, Wang $X$, Shen, Kang L, Fan E. Extraction, Structure and Bioactivities of the Polysaccharides from Fructus corni. Recent Pat Food Nutr Agric 2013; 5(1): 57-61.

12. Wang Lili, Liang Zhengyong, Chen Suiqing. A method for preparing the pigment of Corni Fructus, CN ZL: $201410753765.2[P], 2018$. 